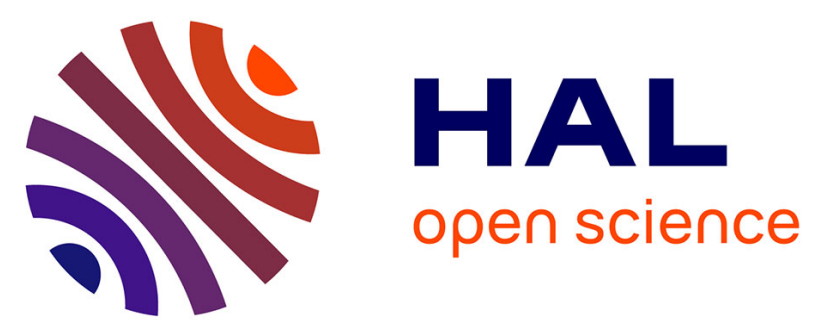

\title{
Overexpression of the urokinase receptor mRNA splice variant uPAR-del4/5 affects tumor-associated processes of breast cancer cells in vitro and in vivo
}

\author{
Sumito Sato, Charlotte Kopitz, Bettina Grismayer, Nathalie Beaufort, Ute
} Reuning, Manfred Schmitt, Thomas Luther, Matthias Kotzsch, Achim

Krüger, Viktor Magdolen

\section{To cite this version:}

Sumito Sato, Charlotte Kopitz, Bettina Grismayer, Nathalie Beaufort, Ute Reuning, et al.. Overexpression of the urokinase receptor mRNA splice variant uPAR-del4/5 affects tumor-associated processes of breast cancer cells in vitro and in vivo. Breast Cancer Research and Treatment, 2010, 127 (3), pp.649-657. 10.1007/s10549-010-1042-5 . hal-00615367

\section{HAL Id: hal-00615367 https://hal.science/hal-00615367}

Submitted on 19 Aug 2011

HAL is a multi-disciplinary open access archive for the deposit and dissemination of scientific research documents, whether they are published or not. The documents may come from teaching and research institutions in France or abroad, or from public or private research centers.
L'archive ouverte pluridisciplinaire HAL, est destinée au dépôt et à la diffusion de documents scientifiques de niveau recherche, publiés ou non, émanant des établissements d'enseignement et de recherche français ou étrangers, des laboratoires publics ou privés. 


\section{Overexpression of the urokinase receptor mRNA splice variant uPAR-del4/5}

affects tumor-associated processes of breast cancer cells in vitro and in vivo

Authors: Sumito Sato ${ }^{1,2}$, Charlotte Kopitz ${ }^{3}$, Bettina Grismayer ${ }^{1}$, Nathalie Beaufort ${ }^{1}$, Ute Reuning ${ }^{1}$, Manfred Schmitt ${ }^{1}$, Thomas Luther ${ }^{4}$, Matthias Kotzsch ${ }^{4}$, Achim Krüger $^{3}$, and Viktor Magdolen ${ }^{1, *}$

Affiliations: ${ }^{1}$ Clinical Research Unit, Department of Obstetrics and Gynecology, Technical University Munich, Ismaninger Str. 22, D-81675 Munich, Germany; ${ }^{2}$ Department of Surgery, Yokohama Asahi Central and General Hospital, 4-20-1 Wakabadai Asahi-ku, Yokohama, 241-0801 Kanagawa, Japan; ${ }^{3}$ Institute of Experimental Oncology and Therapy Research, Technical University Munich, Ismaninger Str. 22, D-81675 Munich, Germany; ${ }^{4}$ Institute of Pathology, Dresden University of Technology, Fetscherstr. 74, D-01307 Dresden, Germany.

Running Title: uPAR-del4/5 overexpression affects tumor-associated processes of breast cancer cells

* Corresponding author: Viktor Magdolen, $\mathrm{PhD}$, Klinische Forschergruppe der Frauenklinik, TU Muenchen, Klinikum rechts der Isar, Ismaninger Str. 22, D-81675 Munich, Germany; Tel: +49-89-4140-2493; Fax: +49-89-4140-7410; E-mail: viktor.magdolen@1rz.tum.de 


\begin{abstract}
Purpose: uPAR, the three-domain membrane receptor of the serine protease urokinase, plays a crucial role in tumor growth and metastasis. Several mRNA splice variants of this receptor have been reported. One of these, uPAR-del4/5, lacking exons 4 and 5, and thus encoding a UPAR form lacking domain DII, is specifically overexpressed in breast cancer and represents a statistically independent prognostic factor for distant metastasis-free survival in breast cancer patients. The aim of the present study was to examine the molecular and cellular properties of the encoded UPAR-del4/5 protein.
\end{abstract}

Methods: To investigate the impact of the uPAR-de14/5 overexpression on in vitro and in vivo aspects of tumor progression (e.g., proliferation, adhesion, invasion, metastatic seeding and/or metastatic growth), we combined the analysis of transfected cancer cell lines with a murine xenograft tumor model.

Results: Increased expression of uPAR-del4/5 in human cancer cells led to reduced adhesion to several extracellular matrix proteins and decreased invasion through Matrigel $^{\mathrm{TM}}$, while cell proliferation was not affected in vitro. Moreover, invasion of uPAR-de14/5 overexpressing cells was not altered by addition of urokinase, while that of uPAR-wild-type overexpressing cells was drastically increased. Accordingly, we observed that, in contrast to uPAR-wild-type, uPAR-de14/5 does not interact with urokinase. On another hand, when overexpressed in human breast cancer cells, uPAR-deH/5 distinctly impaired metastatic dissemination and growth in vivo.

Conclusions: We demonstrate that the uPAR-de14/5 mRNA splice variant mediates tumorrelevant biological processes in vitro and in vivo. Our results thus illustrate how tumorspecific alternative splicing can distinctly impact the biology of the tumor.

Keywords: breast cancer; splice variant; adhesion; invasion; tumor xenograft; uPAR 


\section{Introduction}

The serine protease urokinase-type plasminog en activator (uPA), its serpin-type inhibitor PAI1 , and its cell surface receptor uPAR (CD87), drastically influence tumor cell proliferation, migration, invasion, and metastasis [1-3]. Accordingly, these factors represent important biomarkers in a number of malignancies, including breast cancer [4-6].

uPAR is an ubiquitous $45-60 \mathrm{kDa}$ glycoprotein, which is composed of three homologous domains (DI, DII, and DIII, from the amino - to the carboxy terminus). It is anchored to the plasma membrane by a glycosyl phosphatidyl inositol (GPI) moiety [7]. uPAR exhibits features related to proteolysis as well as cell adhesion: on one hand, upon binding of its canonical ligand uPA, uPAR focuses the extracellular proteolytic network including plasmin and matrix metalloproteinases to the cell surface $[2,7,8]$, on the other, it interacts with the adhesive extracellular matrix (ECM) protein vitronectin as well as with various integrins, thereby regulating cell adhesion and signaling [2, 8, 9]. For these reasons, uPAR is a major regulator of ECM remodeling and cell adhesion/migration $[2,8]$.

Recently, crystal structures of complexes between soluble UPAR (lacking the GPI anchor) and an antagonist peptide (interacting with the UPA binding site of UPAR) or the N-terminal fragment of UPA (ATF; harboring the UPAR binding site) have been determined [10,11]. These studies revealed that the three domains in UPAR are packed closely and form a cone-shaped central cavity which is wide open and displays a significant depth. The major contact areas between UPAR and these ligands are formed by DI and DII residues, respectively. Binding of UPA to UPAR dramatically increases the affinity of UPAR to vitronectin [12]. The crystal structure of the ternary complex of soluble UPAR, ATF and the UPAR-binding domain of vitronectin, SMB, showed that there is no direct contact between SMB and ATF: whereas the UPAR binding site of UPA occupies the central cavity of the receptor, SMB binds to the outer side of DI and the DI-DII linker region [13]. Thus, uPA/uPAR-interaction may stabilize an active conformation of uPAR, leading to its high affinity binding to vitronectin.

Wild-type uPAR (uPAR-WT) is encoded by seven exons. Several mRNA splice variants of UPAR have been identified and their expression analyzed in human cells and tissues [14-16]. One of these splice variants, uPAR-de14/5, lacking exons 4 and 5, and thus encoding a uPAR form lacking domain DII, was found to be specifically overexpressed in breast and ovarian cancer cells [15]. Besides, high uPAR-del4/5 mRNA expression levels were found to be 
significantly associated with short disease-free survival of breast cancer patients $[15,17,18]$. Moreover, uPAR-del4/5 mRNA is a highly sensitive, statistically independent prognostic factor for distant metastasis-free survival in untreated node-negative breast cancer patients [18].

In order to investigate the tumor biological effects of uPAR-del $4 / 5$ splice variant expression, we stably transfected MDA-MB-231 breast cancer cells with expression plasmids encoding either this variant or wild-type uPAR. By proliferation, adhesion, and invasion assays, we first analyzed the phenotype of the cell transfectants in vitro, and then monitored the impact of UPAR-del $4 / 5$ overexpression on experimental metastasis in a xenograft tumor model in mice in vivo. 


\section{Material and methods}

\section{Cell culture and cell transfection}

The human breast adenocarcinoma cell line MDA-MB-231 (American Type Culture Collection [ATCC], Manassas, VA) was cultured in DMEM (Gibco BRL, Eggenstein, Germany) supplemented with $10 \%$ (v/v) fetal calf serum (FCS), $10 \mathrm{mM} \mathrm{HEPES,} 0.55 \mathrm{mM} \mathrm{L}-$ arginine and 0.272 mM L-asparagine (Sigma-Aldrich, Saint-Louis, MO). In some experiments, MDA-MB-435, CAMA-1, MCF-7 breast cancer cells (ATCC), and OV-MZ-6 ovarian cancer cells [19], respectively, were also used. Cells were routinely checked to be free of mycoplasma.

Cloning of pRcRSV-derived expression plasmids encoding uPAR(-variants) has been reported elsewhere [15]. Cells were transfected using Lipofectin ${ }^{\circledR}$ (Invitrogen, Karlsruhe, Germany). Cell transfectants were selected by addition of $1 \mathrm{mg} / \mathrm{ml} \mathrm{G} 418$ to the cell culture medium (Gibco BRL). In an independent transfection experiment, clones of MDA-MB-231-uPARdel $4 / 5$ cells were isolated by limited dilution.

\section{ELISA}

Cells were washed with phosphate-buffered saline (PBS), $\mathrm{pH} 7.4$, then lysed for $60 \mathrm{~min}$ at $4{ }^{\circ} \mathrm{C}$ in Tris-buffered saline (TBS), pH 7.4 containing $1 \%(\mathrm{v} / \mathrm{v})$ Triton-X 100 and a protease inhibitor cocktail ("complete + EDTA"; Roche Diagnostics, Mannheim, Germany). Cell lysates were centrifuged at $13,000 \times \mathrm{g}$ for $15 \mathrm{~min}$ at $4{ }^{\circ} \mathrm{C}$. Protein content was determined using the Micro $\mathrm{BCA}^{\mathrm{TM}}$ protein assay reagent kit (Pierce, Stonehouse, UK). uPAR antigen was determined applying the IMUBIND uPAR ELISA kit \#893 (American Diagnostica Inc., Stamford, CT). uPAR antigen levels in cell lysates are expressed as ng per mg of total protein.

\section{Western blot}

Proteins, separated by electrophoresis on $12 \%$ (w/v) polyacrylamide gels (SDS-PAGE), were transferred to polyvinylidene fluoride membranes (Millipore Corporation, Bedford, MA) in a semi-dry transfer device (Biometra, Göttingen, Germany). Membranes were incubated for 60 min in PBS, pH 7.4, containing $0.1 \%$ (v/v) Tween-20 (PBS-T) and $5 \%(\mathrm{w} / \mathrm{v})$ dried skimmed milk, followed by an overnight incubation with the primary monoclonal antibodies (mAb) IIIF10 or IID7, both directed to UPAR, diluted in PBS-T supplemented with $1 \%$ (w/v) dried 
skimmed milk. The epitope-mapped mAb IIIF10 is directed against DI, mAb IID7 against DII of uPAR [20]. After washes in PBS-T, binding of the antibodies were visualized by incubation of the membranes with a horseradish peroxidase-conjugated secondary goat Ab against mouse Ig (Jackson ImmunoResearch Lab, West Grove, PA), followed by chemoluminescence reaction using ECL(Amersham Biosciences, Little Chalfont, UK).

\section{Immunofluorescence}

Cells were seeded in human fibronectin-coated $(10 \mu \mathrm{g} / \mathrm{ml}$, Becton Dickinson, Heidelberg, Germany) 8-chamber glass slides (Permanox-type Lab-Tek slides; Nunc, Roskilde, Denmark) and cultured overnight. Cell monolayers were fixed in $4 \%(\mathrm{w} / \mathrm{v})$ paraformaldehyde in PBS,

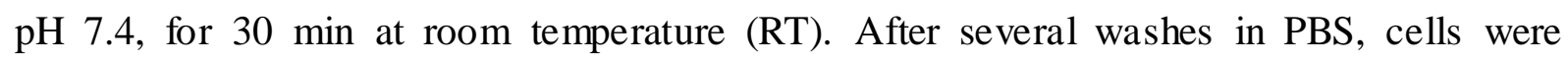
incubated for $1 \mathrm{~h}$ at RT in PBS containing $2 \%(\mathrm{w} / \mathrm{v})$ bovine serum albumin (BSA), and then probed with mAb IIIF10 diluted in PBS, $1 \%$ (w/v) BSA for $1 \mathrm{~h}$ at RT. Cells were washed and incubated for $45 \mathrm{~min}$ at RT in the dark with the secondary Alexa488-labeled goat-anti-mouse IgG (Sigma-Aldrich) diluted in the same buffer. After final washes with PBS, cells were mounted in PBS and fluorescence signal intensity evaluated by confocal laser scanning microscopy (CLSM).

\section{Solid-phase uPA binding assay}

The solid-phase uPA ligand-binding assay was performed in a similar manner as described previously [21]. Briefly, wells of microtiter plates (Maxisorb; Nunc) were coated overnight at $4{ }^{\circ} \mathrm{C}$ with $100 \mu \mathrm{l}$ of rec-uPAR ${ }_{1-277}(1 \mu \mathrm{g} / \mathrm{ml})$. After blocking, $100 \mu \mathrm{l}$ of sample containing the aminoterminal fragment (ATF) of uPA $(250 \mathrm{ng} / \mathrm{ml})$ and $50 \mu \mathrm{l}$ of cell culture supernatants were added to the wells for $1 \mathrm{~h}$ at RT. Cell culture supernatants were derived from vector-control Chinese hamster ovary ( $\mathrm{CHO}$ ) cells or from transfected $\mathrm{CHO}$ cells overexpressing soluble forms of uPAR-WT or uPAR-de14/5 [15]. After four washes, plates were incubated with biotinylated murine mAb \#377 directed to the kringle domain of human uPA (American Diagnostica Inc.) for $1 \mathrm{~h}$ at RT. After washes in PBS, avidin-coupled peroxidase was added for $1 \mathrm{~h}$ at RT. Finally, wells were washed and binding of avidin-peroxidase detected by addition of 3,3',5,5'-tetramethlybenzidine (TMB; $1 \mathrm{mg} / \mathrm{ml}$ ) and $0.003 \%(\mathrm{v} / \mathrm{v}) \mathrm{H}_{2} \mathrm{O}_{2}$ in $0.1 \mathrm{M}$ sodium acetate buffer, $\mathrm{pH}$ 6.0. After termination of the reaction with $0.5 \mathrm{M} \mathrm{H} \mathrm{H}_{2} \mathrm{SO}_{4}$, absorbance was measured at $450 \mathrm{~nm}$. 


\section{Cell-based in vitro assays}

Proliferation assays. Transfected cells were seeded in a 24-well plate at a density of 15,000 cells per well, and incubated for 48 to $96 \mathrm{~h}$ at $37^{\circ} \mathrm{C}$. After washes in PBS, cells were detached using PBS, $0.05 \%$ (w/v) EDTA, and living cells counted in a hemocytometer upon Trypan blue exclusion under a light microscope.

Cell adhesion assays. 96-well plates were coated overnight at $4{ }^{\circ} \mathrm{C}$ with vitronectin (1 $\mu \mathrm{g} /$ well), fibronectin ( $1 \mu \mathrm{g} /$ well), collagen type I or IV ( $1 \mu \mathrm{g} /$ well $)$, all diluted in PBS. Cells were resuspended in culture medium containing $0.5 \%(\mathrm{w} / \mathrm{v}) \mathrm{BSA}$, seeded at a density of 40,000 cells/well, and allowed to adhere for $2 \mathrm{~h}$ at $37^{\circ} \mathrm{C}$. Non-adherent cells were removed by washing with PBS and number of adherent cells quantified by a hexosaminidase activity assay. For this, cells were incubated with p-nitrophenyl-N-acetyl- $\beta$-D-glucosaminide (SigmaAldrich) diluted to $15 \mathrm{mM}$ in a $100 \mathrm{mM}$ sodium citrate buffer, $\mathrm{pH} 5.0,0.5 \%$ (v/v) Triton X100 , for $90 \mathrm{~min}$ at $37^{\circ} \mathrm{C}$. The reaction was terminated by the addition of stop buffer $(0.2 \mathrm{M}$ $\mathrm{NaOH}, 5 \mathrm{mM}$ EDTA) and the optical density recorded at $405 \mathrm{~nm}$.

Cell invasion assays. Invasion assays were performed using Transwell inserts ( $8 \mu \mathrm{m}$ pore size; Becton Dickinson). Basement membrane complex growth factor reduced Matrigel $^{\mathrm{TM}}$ (11.3 $\mathrm{mg} / \mathrm{ml}$ ) was diluted 1:24 in cold PBS and applied to the upper side of the insert. After drying for $24 \mathrm{~h}$ in a laminar hood, inserts were rehydrated with FCS-free DMEM, $0.1 \%(\mathrm{w} / \mathrm{v})$ BSA. Cells were resuspended in culture medium and seeded in the upper chamber of the device at a density of 50,000 cells/chamber. In some experiments, $2 \mu \mathrm{g}$ of proteolytically active highmolecular-weight uPA (ProSpec-Tany TechnoGene, Rehovot, Israel) were added to the upper chamber. The lower chambers were filled with $750 \mu \mathrm{l}$ DMEM supplemented with $10 \%$ (v/v) FCS as a chemoattractant. After a 24 to $48 \mathrm{~h}$ incubation at $37{ }^{\circ} \mathrm{C}$, Matrigel ${ }^{\mathrm{TM}}$ and non-invaded cells, located on the upper side of the insert, were removed with tissue paper, whereas invaded cells on the lower side of the insert were fixed, stained using Diff-Quick (Dade Behring AG, Switzerland), and counted under a light microscope.

\section{Experimental animal model}

MDA-MB-231 cells are tumorigenic and invasive cells, which upon intravenous injection in mice colonize to the lungs [22]. Transfected MDA-MB-231 cells were genetically tagged with the lacZ gene, allowing X-Gal staining, as reported previously [23]. Pathogen-free female 
athymic (nu/nu) mice (4-6 weeks old) were obtained from Charles River Laboratories (Sulzfeld, Germany). Mice were allocated to four groups and intravenously inoculated (tail vein) with $1 \times 10^{6}$ (a) control MDA-MB-231-vector cells $(\mathrm{n}=11)$, (b) batch-transfected MDA-MB-231-uPAR-de14/5 cells $(\mathrm{n}=10)$, (c) cloned MDA-MB-231-uPAR-de14/5 cells $(\mathrm{n}=$ 10), or (d) batch-transfected MDA-MB-231-uPAR-WT cells $(n=9)$. At day 35 post-injection, animals were sacrificed, lungs isolated and the lacZ-tagged tumor cells stained with X-Gal (Roche Diagnostics) [24]. Thereafter, blue stained metastases foci were counted and their size measured, considering nodules with diameter $>0.18 \mathrm{~mm}$ as macrometastases.

\section{Statistical analyses}

Data are expressed as mean \pm SE (standard error) of the indicated number of experiments. Group differences and p-values were calculated by employing the Mann-Whitney test. A pvalue $<0.05$ was considered statistically significant. 


\section{Results}

Generation of UPAR overexpressing breast cancer cell lines

MDA-MB-231 breast cancer cells endogenously express uPAR, as seen by Western blot analysis and immunofluorescence (Fig. 1, see MDA-MB-231 vector cells). Transfection of these cells with a plasmid encoding uPAR-WT resulted in a distinct overexpression of uPAR, which reacts with both mAbs IIIF10 and IID7, directed to domains DI and DII, respectively (Fig. 1a). The observed uPAR reaction pattern was comparable to that reported for other cells (see e.g. [25]). Transfection of cells with uPAR-del4/5 expression plasmid led to the occurrence of a UPAR species that - as expected - migrated faster than UPAR-WT in SDSPAGE and reacted with mAb IIIF10 directed to domain DI, but not with mAb IID7 directed to domain DII (Fig. 1a). Importantly, uPAR-de14/5 overexpression in MDA-MB-231 cells did not affect mRNA expression levels of endogenous uPAR-WT mRNA, as assayed by quantitative RT-PCR (data not shown). The uPAR antigen content, measured by a commercially available ELISA, was distinctly increased in UPAR-WT and uPAR-del4/5 overexpressing cells as compared to the vector control cells (MDA-MB-231 vector control cells: $6.5 \mathrm{ng} / \mathrm{mg}$ total protein; uPAR-WT cells: $51.7 \mathrm{ng} / \mathrm{mg}$; uPAR-de14/5 cells: $12.0 \mathrm{ng} / \mathrm{mg}$ ). It is of note that using this ELISA, we are not able to discriminate between endogenous and overexpressed protein and not between different forms of UPAR. Immunofluorescence further confirmed uPAR overexpression (Fig. 1b). The staining pattern was found to be rather heterogeneous within the transfected cell populations, as expected for batch-transfected cells. Moreover, both uPAR-WT and uPAR-de14/5 displayed an enhanced membrane staining pattern (Fig. 1b), strongly suggesting correct integration of the respective uPAR species into the cell membranes.

In vitro phenotype of $u P A R$-del4/5 overexpressing breast cancer cells

As compared to vector-transfected cells, neither uPAR-WT nor uPAR-de14/5 overexpressing MDA-MB-231 cells displayed significant differences with respect to cell morphology and cell proliferation (data not shown). In contrast, MDA-MB-231-uPAR-de14/5 cells showed a moderate (i.e., 14 to $20 \%)$ but significant $(\mathrm{p}<0.05)$ reduction of their capacity to adhere to certain adhesive ECM proteins, such as vitronectin, fibronectin, and type I collagen (Fig. 2 and Table 1). Interestingly, this reduced adhesive capacity of uPAR-del4/5 overexpressing 
cells was not restricted to the MDA-MB-231 cell line, since transfection of other human breast (i.e., MDA-MB-435, CAMA-1, MCF-7) or ovarian (i.e., OV-MZ-6) cancer cell lines, reduced cell adhesion to various ECM components in the same fashion (Table 1). It is of note that UPAR-WT is an acknowledged pro-adhesive factor, for instance by engagement with its ligand vitronectin, in a number of cell types, including human breast and ovarian cancer cells $[26,27]$.

Next, uPAR-WT and uPAR-de14/5 overexpressing cells were investigated and compared to vector-control cells in a Matrigel ${ }^{\mathrm{TM}}$ invasion assay. As expected, overexpression of uPAR-WT was associated with a distinct, about 3-fold enhanced cell invasive capacity, which was further about 2-fold enhanced in the presence of exogenously added uPA (Fig. 3a, lower panel). Strikingly, MDA-MB-231-uPAR-del4/5 cells displayed a strongly impaired invasion (i.e., about $40 \%$ reduction), which was not affected by the presence of uPA (Fig. 3a, upper panel). In fact, this latter observation was in agreement with solid-phase ligand-binding assays indicating efficient uPA binding to recombinant UPAR-WT, but not to UPAR-de $14 / 5$ protein (Fig. 4). Again, reduced invasion upon uPAR-del4/5 transfection was confirmed in another cancer cell model, namely in human ovarian OV-MZ-6 cancer cells (Fig. 3b).

\section{In vivo phenotype of UPAR-del4/5 overexpressing breast cancer cells}

Lung is a major site for metastatic spread of cancer cells during breast cancer progression [28, 29]. In order to explore the impact of uPAR-del4/5 overexpression in vivo, we intravenously injected mice with MDA-MB-231-vector, -uPAR-WT, or -uPAR-de14/5 cells and analyzed incidence, number, and size of nodules of experimental lung metastases. Most mice of the vector and uPAR-WT groups (10/11 and 7/9, respectively; Fig. 5a) had numerous lung metastases (on the average 57 and 37, respectively; Fig. 5b). Moreover, 16.6 to $28.0 \%$ of the nodules were classified as macrometastases (size over $0.18 \mathrm{~mm}$; Fig. 5c). Remarkably, in the group of mice which had received MDA-MB-231-uPAR-de14/5 cells, 5 out of 10 mice had no detectable lung metastasis (Fig. 5b). Similarly, the number of metastases in colonized lungs (on the average from 57 to 4; Fig. 5b) as well as the percentage of macrometastases (on the average from 16.6 to $0.8 \%$, Fig. $5 \mathrm{c}$ ) was considerably reduced in the uPAR-de14/5 group, as compared to the vector control group. Similar results were observed upon injection of an ind ependently generated MDA-MB-231-uPAR-de14/5 clone (Fig. 5), displaying a comparable antigen level, measured by ELIS A (batch-transfected uPAR-de14/5 cells: $12.0 \mathrm{ng} / \mathrm{mg}$; uPAR- 
de14/5 clone: $10.2 \mathrm{ng} / \mathrm{mg}$ ). These observations suggest that overexpression of uPAR-de14/5 in vivo not only reduced adhesion, but also impaired growth of breast cancer cell-derived lung metastases in vivo. 


\section{Discussion}

Aberrant mRNA splicing is a common feature of malignant disorders. Whether this process results from a general dysregulation of tumor cell functions, and thus represents a by-product of cellular transformation, or whether increased aberrant splicing contributes to the malignant phenotype of cancer cells, is a not yet conclusively answered question [30, 31]. Still, a growing number of evidence demonstrates that tumor-associated mRNA splicing may lead to cancer cell-specific production of new proteins displaying unique functions, which are crucially affecting cancer development. Mis-spliced mRNAs, which escape the so-called nonsense-mediated mRNA degradation, normally lead to synthesis of truncated, mutated, misfolded, and/or unstable proteins. However, by alternative splicing, it is also possible that certain protein domains are deleted from the encoded protein, which may result in loss or gain of function [31]. In a recent study on splice variants of the human Adhesion family of $\mathrm{G}$ protein-coupled receptors, more than half of the identified splice variants appeared to code for functional proteins, lacking one or more extracellular domains, which take part in proteinprotein interactions, without affecting the seven transmembrane region. Thus, alternative splicing apparently can influence interaction of these receptors with other proteins [32].

The recently identified, tumor-associated variant of UPAR, uPAR-de14/5, displays the specific deletion of the complete DII of three-domain uPAR [15]. In fact, uPAR-de14/5 protein, consisting of domains DI+DIII fused together, exhibits unique characteristics significantly affecting the behavior of malignant cells: upon analyses of the impact of uPAR-del4/5 overexpression in human MDA-MB-231 breast cancer cells, we observed a significantly impaired cell adhesion and invasion in vitro, along with a distinctly decreased colonization of lungs (in terms of metastatic nodule occurrence, number, and size) in an experimental metastasis mouse model system.

Binding of UPA to its cell surface receptor UPAR involves all three domains of UPAR [2, 10]. As demonstrated by a sensitive solid-phase ligand-binding assay (Fig. 4) and by an uPA/uPAR-complex ELISA (data not shown), uPAR-del4/5 does not interact with uPA. Consequently, we observed that addition of uPA to uPAR-de14/5 overexpressing cells - in contrast to uPAR-WT overexpressing cells - had no effect on cell invasion through Matrigel ${ }^{\mathrm{TM}}$ (Fig. 3).

$\mathrm{uPA} / \mathrm{uPAR}$ interaction does not only focus proteolytic activity to the tumor cell surface, but is 
also a prerequisite for the binding of another uPAR ligand, the ECM protein vitronectin [12]. Furthermore, interaction of UPA with UPAR is a major determinant of physical and functional interactions of UPAR with a number of integrins $[2,9]$ and is also involved in other tumorassociated functions, e.g. regarding tumor cell survival and angiogenesis [2, 33]. Obviously, uPAR-de14/5 is not capable of modulating these uPA-dependent, tumor-associated functions of uPAR-WT by competing for uPA binding. Still, overexpression of uPAR-de14/5 resulted in a moderate, significantly decreased cell adhesion to an array of adhesive ECM proteins (Fig. 2, Table 1). uPAR-de14/5 also strongly affected cellular invasion in vitro (Fig. 3), a process that depends on both extracellular proteolys is and cell adhesion/detachment capacities. In addition, overexpression of the uPAR-de14/5 splice variant led to a major reduction of experimental metastasis in vivo, compared to both vector control and uPAR-WT overexpressing cells (Fig. 5). It is tempting to speculate that such a phenotype might reflect the capacity of uPAR-de14/5 to behave as a dominant-negative receptor, e.g. via competition with endogenous UPAR-WT for binding to certain integrins such as $\alpha_{5} \beta_{1}$ or $\alpha_{v} \beta_{3}$ and/or via an additional uPAR-WT independent process.

uPAR-de14/5 mRNA is a statistically independent prognostic factor for distant metastasis-free survival in breast cancer patients. High levels of uPAR-de14/5 mRNA are associated with a poor prognosis of patients $[15,17,18]$. However, the results of the present paper, especially regarding the reduced invasive capacity of uPAR-del4/5 overexpressing cells in vitro (Fig. 3) and the reduction in lung colonization of these cells in the in vivo experimental metastasis animal model (Fig. 5) rather advert to the conclusion that the uPAR-de14/5 protein acts as a forceful tumor suppressor. On the one hand, high expression of uPARde14/5 mRNA might reflect the malignant status of the cancer disease, rather than the functions arising thereof at the protein level. On the other hand, as documented for the adverse effects of different PAI-1 concentrations on tumor angiogenesis [34], uPAR-de14/5 protein, depending on the height of its expression level, may display both agonistic and antagonistic properties. Therefore, further extensive studies using clones expressing UPAR-de14/5 protein to a different extent (low $v s$. high expression) and/or variations of uPAR-de14/5 : uPAR-WT protein ratios may help to explore this latter possibility.

The metastatic process requires a complex sequence of events [35]. Invasive tumor cells, originating from an in situ cancer surrounded by an intact basement membrane, degrade ECM proteins, induce reversible changes in cell-cell and cell-ECM adherence, and migrate through 
the ECM. The metastasizing cells then enter circulation, extravasate and disseminate to eventually colonize at a distant site, finally leading to micrometastases and angiogenic metastases. The experimental animal metastasis model used in the present study focuses on the later events of the metastatic process, i.e. metastatic seeding and growth. Here, uPARde14/5 overexpression did not only reduce occurrence and number of metastatic nodules, but also the percentage of macrometastases (Fig. 5), which indeed indicates an impact of the UPAR splice variant on extravasation of circulating tumor cells and/or tissue colonization, as well as on metastatic tumor growth.

In conclusion, although several uPAR mRNA splice variants have been described, some being clearly associated to disease [14-16], no experimental analysis of their cellular properties was reported so far. The present study, combining in vitro and in vivo experimental approaches, clearly demonstrates tumor biologically relevant effects mediated by uPAR-de14/5 in human breast cancer and also ovarian cancer cells. Thus, production of uPAR-del4/5 might represent a striking example for tumor-associated alternative splicing leading to modified protein species strongly modulating tumor biological processes. 


\section{Acknowledgements}

This study was supported in part by grants provided by the Deutsche Krebshilfe e.V., Germany (Grant No. 106 162) to MK and VM, and by the Framework Programme 7 project HEALTH-2007-201279, Microenvimet to AK. We are grateful to Sabine Creutzburg, Katja Richter, and Antje Zobjack for excellent technical assistance.

\section{Competing interests}

The authors declare that they have no competing interests. 


\section{Figure legends}

Fig. 1. Expression of uPAR-WT and uPAR-de14/5 in stably transfected MDA-MB-231 cells.

(a) Lysates from uPAR-WT-, uPAR-de14/5-, or vector-transfected MDA-MB-231 cells $(50 \mu \mathrm{g}$ total protein) were analyzed for uPAR-WT/ uPAR-de14/5 expression by Western blot analysis applying a mAb directed to UPAR domain DI (mAb IIIF10, left-hand panel) or to DII (mAb IID7, right-hand panel) of UPAR.

(b) Analysis of MDA-MB-231 cell transfectants for uPAR-WT / uPAR-de14/5-expression by immunofluorescence using mAb IIIF10 directed to domain DI of UPAR. Typical fluorescent images (lower panel) together with the corresponding differential interference contrast images (upper panel) are depicted. In order to convert fluorescence staining intensity into colors of a glow scale, the look-up table glow Ov/Un LUT provided with the CLSM scanning software was applied: low intensity (red), medium intensity (yellow), and high intensity (white).

Fig. 2. uPAR-de14/5 overexpression reduces the adhesive capacity of human breast cancer cells in vitro.

MDA-MB-231 cells were passed to cell culture plates which were pre-treated with the extracellular matrix proteins vitronectin (VN), fibronectin $(\mathrm{FN})$, and type I (Col I) or type IV (Col IV) collagen. After 2 h of cell cultivation, the number of adherent cells was monitored by the hexosaminidase activity assay. Four independent experiments were performed in triplicates each. The results are given in \%, normalized to the number of adherent vectortransfected cells onto uncoated wells. Whisker box plots indicate the $25^{\text {th }}$ and $75^{\text {th }}$ percentile, the vertical bars indicate the $10^{\text {th }}$ and $90^{\text {th }}$ percentile. The mean value is indicated by a bar within the box. Statistically significant differences $(\mathrm{p}<0.05)$ are indicated by an asterisk. 
Fig. 3. uPAR-de14/5 overexpression reduces the invasive capacity of human breast and ovarian cancer cells in vitro.

(a) Stably transfected MDA-MB-231 breast cancer cells were seeded into the upper compartments of Matrige ${ }^{\mathrm{TM}}$-coated invasion chambers in the absence or presence of $2 \mu \mathrm{g}$ of proteolytically active uPA. After $96 \mathrm{~h}$ of incubation, invaded cells were fixed, stained, and counted. Four independent experiments were performed in duplicates each. The results are given in $\%$, normalized to the number of invaded vector-transfected cells, in the absence of uPA.

(b) Stably transfected human ovarian cancer OV-MZ-6 cells were analyzed (in the absence of $\mathrm{uPA}$ ) for their invasive capacity in a similar manner as described above for the MDA-MB-231 cells. Four independent experiments were performed in duplicates each. The results are given in $\%$, normalized to the number of invaded vector-transfected cells.

Whisker box plots indicate the $25^{\text {th }}$ and $75^{\text {th }}$ percentile, the vertical bars indicate the $10^{\text {th }}$ and $90^{\text {th }}$ percentile. The mean value is indicated by a bar within the box. Statistically significant differences $(p<0.05)$ are indicated by an asterisk.

Fig. 4. uPAR-WT, but not uPAR-del4/5 interacts with uPA.

(a) Schematic representation of the solid-phase uPA-ligand-binding assay ([21]; for details see also Materials and methods). (b) Cell culture supernatants from stably transfected Chinese hamster ovary $(\mathrm{CHO})$ cell lines [15] were added to ATF in the ligand binding assay. Bars represent the amount of ATF bound to immobilized rec-uPAR. Whereas conditioned medium of vector-transfected control cells as well as of cells overexpressing a soluble form of uPARde14/5 did not compete for binding of ATF to rec-uPAR, a significant reduction of recUPAR/ATF interaction was observed in the presence of conditioned medium from cells overexpressing uPAR-WT. Purified, soluble rec-uPAR, interfering with interaction of ATF to immobilized rec-uPAR, was used as a positive control in the assay. 
Fig. 5. Overexpression of uPAR-de14/5 affects lung colonization and metastatic growth of human breast cancer cells.

Stably transfected, lacZ-tagged, MDA-MB-231 cells were inoculated into nude mice via tail vein injection. Mice received either vector control cells (white columns), uPAR-del4/5 cells (gray columns) or UPAR-WT cells (black columns). In addition, an independently generated MDA-MB-231-uPAR-de14/5 transfected cell clone, displaying a comparable uPAR antigen level as the batch-transfected uPAR-del $4 / 5$ cell line (hatched gray columns), was analyzed. Animals were sacrificed at day 35 after injection, lungs were collected and stained with X-Gal. (a) The number of mice presenting lung metastasis is expressed as percentage of total mouse number. (b) Metastases were counted in lungs of the mice. Results are expressed as the mean number of metastases + SE counted in lungs colonized by cancer cells. (c) Metastases with a diameter $\geq 0.18 \mathrm{~mm}$ were considered as macrometastases. Histograms illustrate the mean percentage + SE of macro- versus total metastases in mice lungs. Statistically significant differences $(\mathrm{p}<0.05)$ to the vector control group are indicated by an asterisk. 


\section{Tables}

Table 1. uPAR-de14/5 overexpression reduces the adhesive capacity of human breast and ovarian cancer cells in vitro.

Cell adhesion assays were performed as described in the legend to Fig. 2. Results were normalized to the number of adherent vector-transfected cells to uncoated wells and are expressed as the mean +/- SE. At least four independent experiments were performed in triplicates. The asterisk indicates a statistically significant difference between uPAR-del4/5 overexpressing calls and vector-control cells $(\mathrm{p}<0.05)$.

VN FN Col I Col IV

(\% of the number of adherent vector-transfected cells)

\begin{tabular}{lcccc}
\hline MDA-MB-231 & $86.5 \pm 5.5 *$ & $80.0 \pm 23.1 *$ & $83.7 \pm 11.7 *$ & $89.9 \pm 17.7$ \\
MDA-MB-435 & $87.6 \pm 17.3 *$ & $74.5 \pm 16.7 *$ & $66.7 \pm 25.4 *$ & $82.55 \pm 36.3$ \\
CAMA-1 & $71.7 \pm 17.9 *$ & $57.9 \pm 28.3 *$ & $29.8 \pm 14.8 *$ & $39.4 \pm 21.8 *$ \\
MCF-7 & $93.9 \pm 4.0 *$ & $92.8 \pm 5.3 *$ & $92.5 \pm 2.8 *$ & $98.7 \pm 6.6$ \\
OV-MZ-6 & $89.7 \pm 6.4 *$ & $85.8 \pm 11.2 *$ & $92.5 \pm 6.9 *$ & $95.9 \pm 13.7$
\end{tabular}




\section{References}

1. Blasi F, Sidenius N (2010) The urokinase receptor: Focused cell surface proteolysis, cell adhesion and signaling. FEBS Lett 584:1923-1930

2. Blasi F, Carmeliet P (2002) uPAR: a versatile signalling orchestrator. Nat Rev Mol Cell Biol 3:932-943

3. Reuning U, Magdolen V, Wilhelm O, Fischer K, Lutz V, Graeff H, Schmitt M (1998) Multifunctional potential of the plasminogen activation system in tumor invasion and metastasis. Int J Oncol 13:893-906

4. Harbeck N, Kates RE, Gauger K, Willems A, Kiechle M, Magdolen V, Schmitt M (2004) Urokinase-type plasminogen activator (uPA) and its inhibitor PAI-I: novel tumorderived factors with a high prognostic and predictive impact in breast cancer. Thromb Haemost $91: 450-456$

5. Høyer-Hansen G, Lund IK (2007) Urokinase receptor variants in tissue and body fluids. Adv Clin Chem 44:65-102

6. Harris L, Fritsche H, Mennel R, Norton L, Ravdin P, Taube S, Somerfield MR, Hayes DF, Bast RC (2007) American Society of Clinical Oncology 2007 update of recommendations for the use of tumor markers in breast cancer. J Clin Oncol 25:52875312

7. Ploug M (2003) Structure-function relationships in the interaction between the urokinase-type plasminogen activator and its receptor. Curr Pharm Des 9:1499-1528

8. Smith HW, Marshall CJ (2010) Regulation of cell signalling by uPAR. Nat Rev Mol Cell Biol 11:23-36

9. Reuning U, Magdolen V, Hapke S, M. Schmitt M (2003) Molecular and functional interdependence of the urokinase-type plasminogen activator system with integrins. Biol Chem 384:1119-1131

10. Llinas P, Le Du MH, Gårdsvoll H, Danø K, Ploug M, Gilquin B, Stura EA, Ménez A (2005) Crystal structure of the human urokinase plasminogen activator receptor bound to an antagonist peptide. EMBO J 24:1655-1663

11. Huai Q, Mazar AP, Kuo A, Parry GC, Shaw DE, Callahan J, Li Y, Yuan C, Bian C, Chen L, Furie B, Furie BC, Cines DB, Huang M (2006) Structure of human urokinase 
plasminogen activator in complex with its receptor. Science $311: 656-659$

12. Gårdsvoll H, Ploug M (2007) Mapping of the vitronectin-binding site on the urokinase receptor: involvement of a coherent receptor interface consisting of residues from both domain I and the flanking interdomain linker region. J Biol Chem 282:13561-13572

13. Huai Q, Zhou A, Lin L, Mazar AP, Parry GC, Callahan J, Shaw DE, Furie B, Furie BC, Huang M (2008) Crystal structures of two human vitronectin, urokinase and urokinase receptor complexes. Nat Struct Mol Biol 15:422-423

14. Stewart CE, Sayers I (2009) Characterisation of urokinase plasminogen activator receptor variants in human airway and peripheral cells. BMC Mol Biol 10:75

15. Luther T, Kotzsch M, Meye A, Langerholc T, Fussel S, Olbricht N, Albrecht S, Ockert D, Muehlenweg B, Friedrich K, Grosser M, Schmitt M, Baretton G, Magdolen V (2003) Identification of a novel urokinase receptor splice variant and its prognostic relevance in breast cancer. Thromb Haemost 89:705-717

16. Pyke C, Eriksen J, Solberg H, Nielsen BS, Kristensen P, Lund LR, Danø K (1993) An alternatively spliced variant of $\mathrm{mRNA}$ for the human receptor for urokinase plasminogen activator. FEBS Lett 326:69-74

17. Kotzsch M, Farthmann J, Meye A, Fuessel S, Baretton G, Tjan-Heijnen VC, Schmitt M, Luther T, Sweep FC, Magdolen V, Span PN (2005) Prognostic relevance of uPAR-de14/5 and TIMP-3 mRNA expression levels in breast cancer. Eur J Cancer 41:2760-2768

18. Kotzsch M, Sieuwerts AM, Grosser M, Meye A, Fuessel S, Meijer-van Gelder ME, Smid M, Schmitt M, Baretton G, Luther T, Magdolen V, Foekens JA (2008) Urokinase receptor splice variant uPAR-de14/5-associated gene expression in breast cancer: identification of rab31 as an independent prognostic factor. Breast Cancer Res Treat $111: 229-240$.

19. Möbus V, Gerharz CD, Press U, Moll R, Beck T, Mellin W, Pollow K, Knapstein PG, Kreienberg R (1992) Morphological, immunohistochemical and biochemical characterization of 6 newly established human ovarian carcinoma cell lines. Int J Cancer $52: 76-84$ 
20. Luther T, Magdolen V, Albrecht S, Kasper M, Riemer C, Kessler H, Graeff H, Müller M, Schmitt M (1997) Epitope-mapped monoclonal antibodies as tools for functional and morphological analyses of the human urokinase receptor in tumor tissue. Am J Pathol 150:1231-1244

21. Goretzki L, Bognacki J, Koppitz M, Rettenberger P, Magdolen V, Creutzburg S, Hammelburger J, Weidle UH, Wilhelm O, Kessler H, Graeff H, Schmitt M (1997) Quantitative assessment of interaction of urokinase-type plasminogen activator and its receptor (CD87) by use of a solid-phase uPA-ligand binding assay. Fibrinol Proteol $11: 11-19$

22. Krüger A, Soeltl R, Sopov I, Kopitz C, Arlt M, Magdolen V, Harbeck N, Gänsbacher B, Schmitt M (2001) Hydroxamate-type matrix metalloproteinase inhibitor batimastat promotes liver metastasis. Cancer Res 61:1272-1275

23. Kopitz C, Anton M, Gänsbacher B, Krüger A (2005) Reduction of experimental human fibrosarcoma lung metastasis in mice by adenovirus-mediated cystatin $\mathrm{C}$ overexpression in the host. Cancer Res $65: 8608-8612$

24. Krüger A, Schirrmacher V, Khokha R (1998) The bacterial lacZ gene: an important tool for metastasis research and evaluation of new cancer therapies. Cancer Metastasis Rev 17:285-294.

25. Beaufort N, Leduc D, Eguchi H, Mengele K, Hellmann D, Masegi T, Kamimura T, Yasuoka S, Fend F, Chignard M, Pidard D (2007) The human airway trypsin-like protease modulates the urokinase receptor ( $\mathrm{UPAR}, \mathrm{CD} 87$ ) structure and functions. Am J Physiol Lung Cell Mol Physiol 292:1263-1272

26. Wei Y, Lukashev M, Simon DI, Bodary SC, Rosenberg S, Doyle MV, Chapman HA (1996) Regulation of integrin function by the urokinase receptor. Science 273:15511555

27. Xue W, Mizukami I, Todd RF, Petty HR (1997) Urokinase-type plasminogen activator receptors associate with beta1 and beta3 integrins of fibrosarcoma cells: dependence on extracellular matrix components. Cancer Res 57:1682-1689 
a
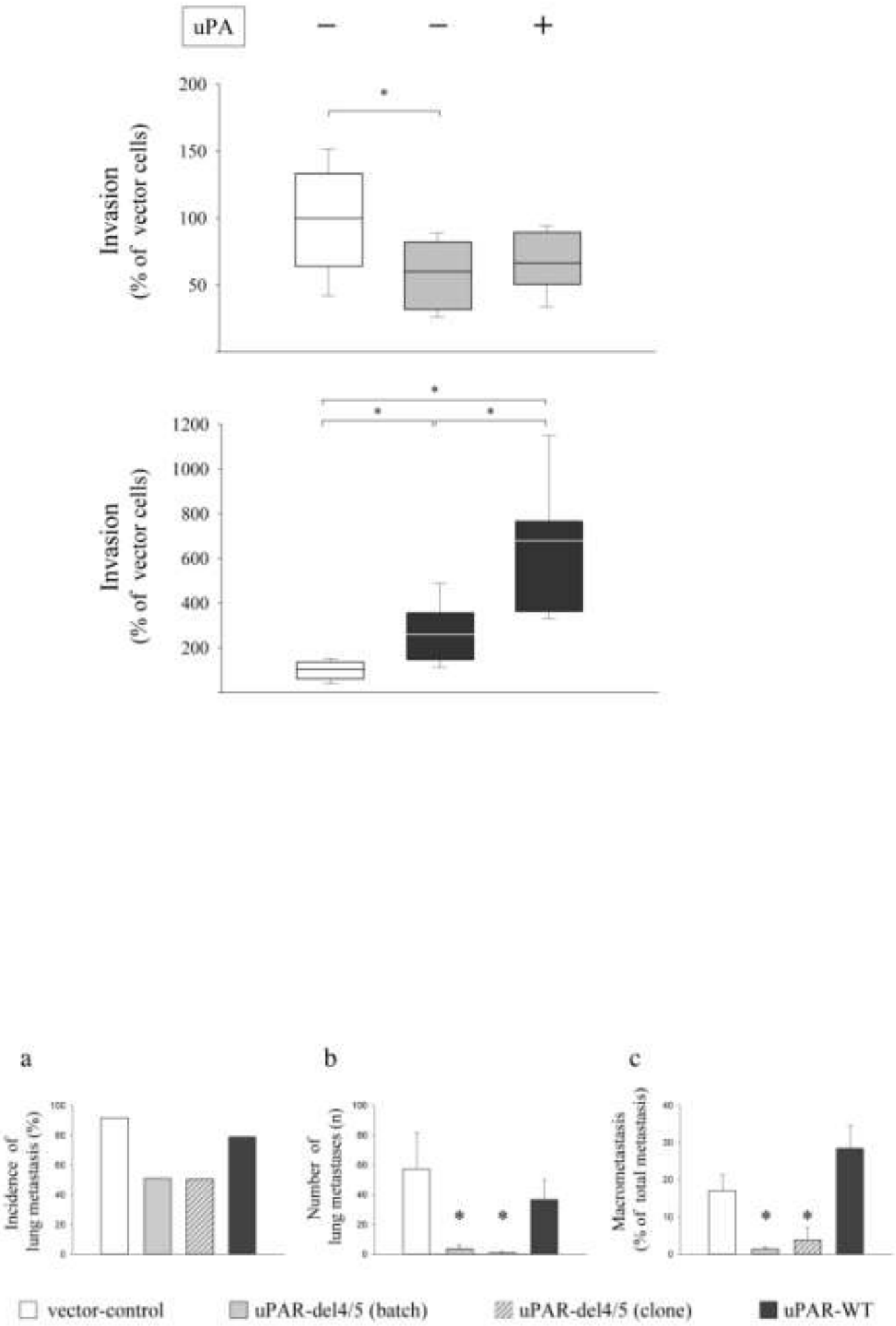

Figure 5 